Published in final edited form as:

Health Psychol. 2018 March ; 37(3): 238-246. doi:10.1037/hea0000547.

\title{
Psychological Status and Weight Variability Over Eight Years: Results from Look AHEAD
}

\author{
Carly R. Pacanowski, \\ University of Delaware \\ Jennifer A. Linde, \\ University of Minnesota \\ Lucy F. Faulconbridge, \\ University of Pennsylvania \\ Mace Coday, \\ University of Tennessee Health Science Center \\ Monika M. Safford, \\ Department of Medicine, Weill Cornell Medicine \\ Haiying Chen, \\ Wake Forest University School of Medicine
}

\section{Susan Z. Yanovski,}

National Institute of Diabetes and Digestive and Kidney Diseases, NIH

Linda J. Ewing,

University of Pittsburgh

\section{Rena Wing,}

The Miriam Hospital, Brown Medical School

Robert W. Jeffery, and

School of Public Health, University of Minnesota

The Look AHEAD Research Group

\begin{abstract}
Objective-Cross-sectional studies suggest an association between weight cycling and psychological status. Although this is often interpreted as suggesting that weight cycles "cause" psychological distress, the relationship could be bi-directional. This study provides a prospective analysis of the bi-directional association between weight variability and psychological status over an eight-year period in overweight/obese adults with type 2 diabetes.
\end{abstract}

Methods-Data were from the first eight years of Look AHEAD, a randomized controlled trial comparing health outcomes in individuals with type 2 diabetes assigned to an intensive lifestyle

Corresponding author: Carly R. Pacanowski, 026 North College Avenue, 015 Carpenter Sports Building, Newark, DE 19716. Phone: 302.831.1109; cpacanow@udel.edu; no fax available. 
intervention designed to produce weight loss or a diabetes education and support control group. Psychological status (mental health, depressive symptoms, binge eating) was assessed via surveys and were examined in relation to weight variability at both baseline and year eight. Weight variability was derived from eight possible annual measurements from participants who had a minimum of three consecutive body weight measurements $(n=4,774)$ and operationalized as the number of year-to-year cycles and the coefficient of variation across all available weight measurements.

Results-Controlling for study group, higher baseline scores on mental health (SF-36 Mental Component Summary) and lower levels of depressive symptomatology (Beck Depression Inventory) and binge eating (Questionnaire on Eating and Weight Patterns) were associated with significantly less subsequent weight variability. The prospective association between weight variability and psychological status at year eight was less robust.

Conclusions-These results suggest that the cross-sectional relationship between weight variability and psychological status is due primarily to poorer psychological function preceding greater weight instability.

\section{Keywords}

body weight; mental health; depressive symptoms; binge eating; body weight change

In a recent Gallup poll, more than half of American adults reported wanting to lose weight. Over a quarter reported seriously trying to do so at the time of survey (Gallup, 2014). Regrettably, the majority of individuals who successfully lose weight, regain most, if not all, of weight lost within five years of completing a weight-loss program (Anderson, Konz, Frederich, \& Wood, 2001). Weight loss and regain associated with unsuccessful weight control attempts have led to speculation about the potential negative physical and psychological health consequences of weight cycling (Brownell \& Rodin, 1994; French \& Jeffery, 1994). Most of the literature on correlates of weight cycling has been devoted to physiological consequences (e.g. heart disease, metabolic syndrome, morbidity, mortality) (Casazza et al., 2013; Montani, Schutz, \& Dulloo, 2015; Vergnaud et al., 2007).

Psychological factors have been less studied, with mixed results. Some studies have found a significant relationship between weight cycling and mental health (Foreyt et al., 1995), depressive symptoms (de Zwaan, Engeli, \& Müller, 2015), and binge eating (Bartlett, Wadden, \& Vogt, 1996; Dalle Grave, Todisco, Oliosi, \& Marchi, 1996; de Zwaan et al., 2015; Marchesini et al., 2004; Spitzer et al., 1992; Venditti, Wing, Jakicic, Butler, \& Marcus, 1996). Others have failed to find a relationship between weight cycling and mental quality of life (Strychar et al., 2009), depressive symptoms (Bartlett et al., 1996; Clark \& King, 2000; Dalle Grave et al., 1996; Foreyt et al., 1995; Foster, Wadden, Kendall, Stunkard, \& Vogt, 1996; Kuehnel \& Wadden, 1994; Messier et al., 2014; Osborn, Forys, Psota, \& Sbrocco, 2011; Simkin-Silverman, Wing, Plantinga, Matthews, \& Kuller, 1998), or binge eating (Foster et al., 1996; Kuehnel \& Wadden, 1994; Osborn et al., 2011). As an example of these inconsistent findings, Bartlett, Wadden \& Vogt (1996) studied cross-sectional relationships in 130 obese women with an average age of $41.1 \pm$ years. Weight cycling was assessed using the Weight and Lifestyle Inventory (Wadden \& Foster, 2006), totaling the number of times the individual had dieted, and dividing this into quartiles. Depressive symptoms were 
assessed using the Profile of Mood States (McNair, Lorr, Droppleman, \& others, 1981), and binge eating was assessed with both the Questionnaire on Eating and Weight Patterns (QEWP) (Spitzer et al., 1993) and the Binge Eating Scale (BES) (Gormally, Black, Daston, \& Rardin, 1982). Though they did not find a relationship between weight cycling and depressive symptoms or binge eating using the QEWP, a positive relationship between weight cycling and binge eating was found using the BES $(r=0.24, p=0.003)$ (Bartlett et al., 1996). More recently, DeZwaan, Engeli, and Muller (2015) investigated the relationship between weight cycling, binge eating and depression in 923 overweight and obese adults. Average age was in the mid-forties and did not differ between severe-cyclers, defined by losing at least $10 \mathrm{~kg}$ on three or more occasions, and non-cyclers (all other participants). Depression was assessed with the Patient Health Questionnaire-9 (Kroenke, Spitzer, \& Williams, 2001) and binge eating was assessed using the Eating Disorder ExaminationQuestionnaire (Fairburn, Beglin, \& Fairburn, 2008). Severe cyclers (as compared to noncyclers) reported a significantly higher depression rating $(6.2 \pm 4.7$ versus $4.0 \pm 3.6, \mathrm{p}=$ 0.02 ) and were more significantly more likely to report binge eating in the past 28 days $(29.5 \%$ versus $9.9 \%, \mathrm{p}<0.001)$.

In addition to divergent findings due to defining weight cycling or other issues of assessment, another possible reason for discrepant findings could be study design. Most published data on weight cycling and psychological outcomes have been cross sectional, which confounds causal interpretations (Bartlett et al., 1996; Dalle Grave et al., 1996; de Zwaan et al., 2015; Foreyt et al., 1995; Friedman, Schwartz, \& Brownell, 1998; Kensinger, Murtaugh, Reichmann, \& Tangney, 1998; Kuehnel \& Wadden, 1994; Marchesini et al., 2004; Osborn et al., 2011; Simkin-Silverman et al., 1998; Spitzer et al., 1992; Strychar et al., 2009; Venditti et al., 1996). Only three studies prospectively evaluated this relationship and none found evidence of weight variability predicting poorer psychological outcomes, conceptualized as mood/depressive symptoms, depression, or binge eating (Clark \& King, 2000; Foster et al., 1996; Messier et al., 2014). Two of these studies were limited in sample size, and the remaining study had a short follow-up interval. Furthermore, these three prospective studies posited weight cycling as a predictor of psychological outcomes; however, it is possible that the relationship is bidirectional: psychological factors could predict weight cycling. Poorer psychological status predicts greater attrition from weight loss programs (e.g. Sherwood, Jeffery, \& Wing, 1999), less weight loss and greater chance of regain (Elfhag \& Rössner, 2005). In addition, mechanistically, poorer psychological status (e.g. negative emotion) is associated with greater food intake (Chua, Touyz, \& Hill, 2004; Geliebter \& Aversa, 2003), which, over time, could lead to weight gain, desire to lose weight, weight loss, and regain (Stein et al., 2007; Stojek et al., 2016). Thus, additional prospective data on the antecedents, correlates and consequences of weight variability would be helpful in resolving concerns about the potential adverse psychological consequences of repeated weight loss and regain (Foster, Sarwer, \& Wadden, 1997).

The Look AHEAD (Action for Health in Diabetes) trial provides a unique opportunity to study weight variability and psychological factors including mental health, depressive symptomology, and binge eating behaviors, in overweight and obese individuals with Type 2 Diabetes. A large cohort of overweight and obese individuals has been followed for more than eight years, half of whom received an intensive behavioral intervention to help them 
lose weight and sustain weight loss. Measured weights are available for eight years, as are repeated measurements of self-reported mental health, depressive symptomatology and binge eating. The purpose of this study is twofold. First, to examine baseline psychological predictors (quality of life, depressive symptomology, and binge eating) of weight variability in this cohort of overweight and obese adults with type 2 diabetes over a period of eight years. Second, because the relationship between weight variability and psychological status may be bidirectional, to examine weight variability over eight years as a predictor of psychological outcomes at year eight. It was hypothesized that less favorable psychological status at baseline predicts more weight variability over eight years, and that greater weight variability predicts poorer psychological outcomes at study end (year eight); hence, the relationship between psychological status and weight variability is bidirectional.

\section{Method}

\section{Design \& Sample}

The design of the Look AHEAD trial has been described in detail (Ryan et al., 2003). In summary, Look AHEAD was a multicenter, randomized, clinical trial designed to determine whether an intensive lifestyle intervention to achieve weight loss through caloric restriction and increased physical activity would decrease cardiovascular morbidity and mortality among overweight or obese adults with type 2 diabetes. Inclusion criteria included being between the ages of 45 and 74, having a Body Mass Index (BMI) of $\geq 25.0 \mathrm{~kg} / \mathrm{m}^{2}$, and type 2 Diabetes Mellitus. Excluded were those who were pregnant or nursing, or had severe psychiatric (e.g. psychosis, bipolar disorder) or physical illnesses known to shorten the lifespan (e.g. HIV, renal disease) (Ryan et al., 2003). Look AHEAD also aimed to recruit and establish a sample consisting of more than $1 / 3$ racial and ethnic minority populations, thus studying a diverse sample. Each center obtained approval from its respective institutional review board (IRB) regarding procedures and consenting of individuals prior to study participation. A total of 5,145 participants were randomized to either an intensive lifestyle intervention group (ILI) or to a control group that received Diabetes Support and Education (DSE). The ILI treatment was developed based on the Diabetes Prevention Program (Diabetes Prevention Program Research Group, 2002b, 2002a) and consisted of both individual and group sessions delivered by a multidisciplinary care team. Participants were encouraged to self-monitor their dietary intake and physical activity and to strive to achieve individually calculated energy intake goals to achieve weight management and increase physical activity to at least 175 minutes per week. Adherence was supported by evidence-based behavior modification strategies specific to phase of weight loss versus maintenance as previously described (Wadden \& Look AHEAD Research, 2006). Sessions and contact with care providers were scheduled more frequently in the first year (i.e. three group sessions and one individual session per month for the first six months and two group sessions and one individual session for months 7-12), and less frequently after the initial year of intervention (i.e. one in-person and one phone/electronic contact per month for months 13-48; one in-person contact per year during and after month 49) (Ryan et al., 2003). Refresher and maintenance meetings were in place to help manage weight regain. The comparison group, DSE, was provided with three optional sessions per year which focused 
on education about nutrition, physical activity, and social support (Wesche-Thobaben \& The Look AHEAD Research Group, 2011).

Psychological Status-This study focuses on the following psychological status measures obtained at baseline and year 8 .

Mental Health: Mental Health was assessed with the Short Form -36 (SF-36) Mental Component Summary (MCS). This 36-item questionnaire has been widely used to assess physical and mental functioning as related to overall quality of life, and its adequate psychometric properties have been documented (McHorney, Ware Jr, \& Raczek, 1993; Ware Jr \& Sherbourne, 1992). In this study, the MCS score was used to operationalize mental health/well-being and as a predictor and consequence of weight cycling. Scores for the MCS range from 0 (poorest mental health/well-being) to 100 (exceptional mental health/wellbeing). Cronbach's alpha for the MCS at baseline in this sample was 0.93 .

Depressive symptoms: Depressive symptoms were measured using the original Beck Depression Inventory (BDI-I) (A. T. Beck, Ward, Mendelson, Mock, \& Erbaugh, 1961), a well-studied instrument with satisfactory psychometric properties in nonpsychiatric populations (Aaron T. Beck, Steer, \& Carbin, 1988). The BDI has 21 items; however, since one of the items asks about weight loss, this item was removed from our analyses. The resulting $\mathrm{BDI}$ is a 20-question assessment depressive symptoms with scores ranging from 0 (no reported depressive symptoms) to 60 (clinically significant number and severity of reported depressive symptoms). Cronbach's alpha for the BDI at baseline in this sample was 0.82 .

Binge eating: Binge eating was assessed using the Questionnaire on Eating and Weight Patterns (QEWP) (Spitzer et al., 1993). To be considered to have self-reported binge eating, an individual was required to have answered "yes" to both of the following items:

1. During the past 6 months, did you ever eat what most people, like your friends, would think was a really big amount of food? If response was 'yes', follow up question was: Did you ever eat a really big amount of food within a short time (2 hours or less)?

2. When you ate a really big amount of food, did you ever feel that you could not stop eating? Did you feel that you could not control what or how much you were eating?

Weight Variability-Weights were measured annually by staff members who were blind to the intervention condition. Drawing upon previous researchers' recommendations for operationalizing weight variability and weight maintenance (Cutter et al., 1996; Stevens, Truesdale, McClain, \& Cai, 2006), weight variability was operationalized using annual body weight follow-up data in the following two ways: (1) individual weight coefficient of variation, which is the unit-less numerical representation of an individual's deviance relative to their mean weight; and (2) the number of times in which change in weight from the previous year was at least $3 \%$ of weight the current year, and in the succeeding year the change was at least $\pm 3 \%$, but the sign was reversed. Three percent was used as a cut-off 
based on the definition of weight maintenance being $\pm 3 \%$ of original weight (Stevens et al., 2006). Thus, if an individual had 8 years of follow-up measurements, they would have a maximum amount of 6 possible 'weight variable' cycles. If a person gained $1.5 \%$ of their weight from year 5 to year 6 and continued with another $1.5 \%$ gain from year 6 to year 7 , they would not be considered to have had any weight variable cycles over this period.

\section{Statistical Analyses}

Baseline characteristics were compared across the number of weight variable cycles. Analysis of Variance models were used for continuous variables and chi-square tests were used for categorical variables. The association between weight coefficient of variation and baseline psychological measures was analyzed using general linear models (GLM). Since the distribution of weight coefficient of variation was highly skewed, log-transformation was used in GLMs. The estimated regression coefficients and corresponding confidence intervals were back-transformed (exponentiated) to the natural scale for ease of interpretation (Manikandan, 2010). Ordinal logistic regression models were used to assess the association between baseline psychological measures and the number of weight cycles. Proportional odds assumption was examined using score test for each model. Odds ratios (OR) and associated 95\% confidence intervals (CI) were reported. All models were adjusted for group assignment by including group as a covariate.

For weight variability predicting year eight psychological outcomes, one model was run including weight variability (either number of weight cycles or weight coefficient of variation), baseline values of the psychological outcome measures, and baseline characteristics including age, gender, race, BMI, history of cardiovascular disease (CVD), and randomization assignment. Since the interventions were designed to be most intensive during the first year in Look AHEAD, percent weight change from baseline to year 1 was adjusted for in all analyses (by including this value as a covariate in the models), in addition to weight change over the course of the eight-year period. Another "unadjusted" model was run using only baseline value of the outcome variable and randomization assignment. The regression coefficients represent the mean change in a continuous outcome for every unit increase in weight variability. Binge eating was analyzed as a binary outcome using logistic regression models. Model predictors were similar to those used in the GLMs. Odds ratios $(\mathrm{OR})$ and associated $95 \%$ confidence intervals (CI) were reported. All analyses were performed using SAS 9.4. A two-sided p-value of less than 0.05 was considered statistically significant.

\section{Results}

Of the 5,145 participants randomized to the ILE or DSE group, 4,774 had at least three consecutive annual weight measurements allowing us to assess number of weight cycles. Continuous characteristics are displayed in Table 1. The mean age of the sample at baseline was $58.7 \pm 6.9$ years and mean BMI was $35.9 \pm 5.9 \mathrm{~kg} / \mathrm{m}^{2}$. Mean scores for MCS was 54.9 \pm 8.0. Mean BDI score was low, indicating few reported depressive symptoms (Beck, Steer, $\&$ Carbin, 1988). About $93 \%$ of the sample met the criteria for minimal depression, and 5\% for mild depression. 
Table 2 displays the number of weight cycles experienced according to categorical baseline characteristics. In females, about half (52.5\%) experienced no weight cycles, 30\% experienced one weight cycle, $11.9 \%$ experienced two weight cycles, and $5.6 \%$ experienced three or more weight cycles. The proportion of females experiencing weight cycles was significantly greater than the proportion of males $(47.5 \%$ versus $39 \%$, respectively; $p$ $<0.0001)$. The proportion who experienced none, one, two, or three or more weight cycles did not differ by race/ethnicity. Although the effect of study group on weight cycles was not significant, $57.5 \%$ in ILI and 54.3\% in DSE experienced no weight cycles ( $\mathrm{p}=0.056)$. Though the percentage of participants having no, one, two, or three or more weight cycles was not significantly different by study group, the mean weight CV in the ILI group was significantly higher than that of the DSE group (4.1\%, CI: 4.0, 4.2 versus 3.8\%, CI: 3.7, 3.8, $\mathrm{p}<0.0001)$. To address the potential role of study group on the relationship between psychological variables and weight cycling, data were used from year 1 onward (baseline to year 1 was the intensive portion of the treatment), and adjusted for study group in all analyses.

Binge eating was reported by $12.7 \%$ of the sample at baseline; weight cycles were significantly more likely in those reporting binge eating symptoms $(p=0.035)$. Of the participants reporting binge eating, just over half (50.7\%) did not experience any weight cycles, about a third (30.5\%) experienced one weight cycle, $12.6 \%$ experienced two weight cycles, and $6.1 \%$ experienced three or more weight cycles. Of the participants not reporting binge eating at baseline, $56.6 \%$ did not experience any weight cycles, $28.2 \%$ experienced one weight cycle, $10.2 \%$ experienced two weight cycles, and $5.0 \%$ experienced three or more weight cycles.

Table 3 displays predictors of number of weight cycles (none, one, two, three or more) over eight years controlling for study group. Components of quality of life, depressive symptomology, and binge eating at baseline all significantly predicted the chance of having more weight cycles. For every 1-unit increase in MCS, there was a $1 \%$ decrease in the odds of having more weight cycles ( $\mathrm{OR}=0.99$; CI: $0.98,1.00 ; \mathrm{p}=0.008$ ). For every 1 -unit increase in baseline BDI, the odds of having more weight cycles increased by $2 \%(\mathrm{OR}=$ 1.02; CI: 1.01, 1.03; $\mathrm{p}=0.001)$. Finally, those who reported binge eating at baseline had 1.28 times greater odds of more weight cycles compared with those who did not report binge eating at baseline $(\mathrm{OR}=1.28 ; \mathrm{CI}: 1.09,1.50 ; \mathrm{p}=0.003)$.

Since the literature on weight cycling has advised using both number of cycles and weight coefficient of variation (CV) (Cutter et al., 1996), Table 4 presents results using weight CV. Values in this table are back-transformed values from the log scale controlling for study arm. The results seen in Table 4 with CV are similar to Table 3, except for the relationship between MCS and weight CV not being significant. For every 1-unit increase in BDI, there was a $1 \%$ increase in weight $\mathrm{CV}($ Beta $=1.01 ; \mathrm{CI}: 1.00,1.01 ; \mathrm{p}=0.0002)$. Individuals who reported binge eating at baseline experienced a mean weight $\mathrm{CV}$ of $4.3 \%$ (CI for Beta: 4.14 , 4.52), while those who did not report binge eating at baseline experienced an average weight CV of 3.8\% (CI for Beta: 3.79, 4.92), ( $\mathrm{p}<0.0001$ ). Thus, the weight of individuals who reported binge eating varied more from their mean weight over eight years than those who did not report binge eating. 
Tables 5a, 5b, 6a, and $6 \mathrm{~b}$ display results from fully and minimally adjusted models looking at weight variability over eight years as a predictor of year-eight psychological outcomes. In the fully adjusted models, number of weight cycles did not significantly predict year eight psychological outcomes, but weight CV significantly predicted poorer psychological outcomes for MCS and depressive symptoms. Every $1 \%$ increase in weight CV was associated with a 0.13-point decrease in and MCS (Beta \pm SE $=-0.13 \pm 0.05 ; \mathrm{p}=0.0114)$ and a 0.07-point increase in depressive symptoms (Beta $\pm \mathrm{SE}=0.07 \pm 0.03 ; \mathrm{p}=0.0118$ ). In the minimally adjusted models, weight variability, both as a $1 \%$ increase in weight $\mathrm{CV}$ and a 1-unit increase in number of weight cycles, significantly predicted decreases in MCS at year eight $($ Beta $\pm \mathrm{SE}=-0.13 \pm 0.05 ; \mathrm{p}=0.0054 ;$ Beta $\pm \mathrm{SE}=-0.32 \pm 0.15 ; \mathrm{p}=0.0312$,

respectively). Weight variability did not predict binge eating at year eight in any models.

\section{Discussion}

In this sample of over 4,700 adults with overweight/obesity and type 2 diabetes, poorer psychological status at baseline (indicated by lower scores on mental well-being and higher scores on depression and presence of binge eating) was associated prospectively with more weight variability over the following eight years. Women and individuals reporting bingeeating symptoms at baseline were significantly more likely to experience a greater number of weight cycles over this eight-year period than men or individuals not reporting bingeeating symptoms at baseline. In contrast, there was limited support for weight variability over eight years predicting poorer psychological functioning at year eight; although in the hypothesized direction, the associations were inconsistently significant and overall less robust. When considering these findings, it must be noted; however, that statistical significance does not necessarily translate to clinical meaningfulness. The odds ratios presented translate to effects that are very small, or small (Chen, Cohen, \& Chen, 2010). At the same time, there has been hesitancy to determine minimal clinically meaningful cutoffs for outcomes such as health-related quality of life, noting that small differences can still be clinically meaningful (Hays \& Woolley, 2006; Jaeschke, Singer, \& Guyatt, 1989). Overall, the findings reported here should be interpreted in the context of the sample size and sample population.

The present study is unique and adds to the literature by providing a large sample of repeated weight measures with long-term follow up of both psychological factors and objective measures of weight, thus allowing for examination of the bi-directional prospective relationship. These findings suggest that the cross-sectional association most often observed between weight variability and psychological status may be due primarily to poorer psychological status predicting greater weight cycling rather than unstable weight management leading to greater psychological distress. These findings are in agreement with another fairly large study of adults with diabetes $(n=1,100)$, which used self-report to operationalize weight cycling. Women were significantly more likely to experience weight cycles than men, and those who had major depression were significantly more likely to report having experienced weight cycles than those who did not have major depression (Messier et al., 2014). 
The findings reported in this manuscript also concur with evidence from other studies showing that weight variability does not predict poorer psychological outcomes (Clark \& King, 2000; Foster et al., 1996; Messier et al., 2014). In addition, limited evidence was found to support the notion that psychological distress is negative sequela of weight cycling. In this study, only weight CV (and not number of cycles) significantly predicted poorer psychological outcomes, and the effect was very small. It is likely that the larger sample size and long-term follow up allowed for the identification of weak associations between weight cycling and psychological outcomes that other studies were not able to detect due to power limitations.

This study also provides important data suggesting that weight cycles occur less frequently than has been previously assumed. Over half of the participants had no weight cycles over the eight years, and less than $15 \%$ had 2 or more cycles. Women experienced more weight cycles than men, but no differences were observed across ethnic/racial groups. Further studies are needed to determine whether this low frequency of weight cycles is a widespread phenomenon, or occurred particularly in this sample (individuals with type 2 diabetes who were enrolled in a clinical trial of lifestyle intervention for weight loss). A unique aspect of this study was the ability to analyze the frequency of weight cycles in both participants randomized to an intensive weight loss intervention and a self-education control group. Because intensive lifestyle interventions typically produce a pattern of significant weight loss, followed by limited weight regain (as occurred in Look AHEAD), they are often criticized for creating weight cycles. Thus, it is very important to note that $57.5 \%$ of participants in the lifestyle intervention group in Look AHEAD had no weight cycles over eight years, compared to $54.3 \%$ in the control group ( $\mathrm{p}=.056)$.

Strengths of the study include the prospective design, objective weight measures, and the large sample size, with a balance of male and female volunteer participants and racial and ethnic diversity (more than $1 / 3$ from racial and ethnic minority populations), which make findings generalizable to the population of older adults with Type 2 diabetes. The findings are limited however, by the low rates of depressive symptomatology and binge eating in this sample. Relatedly, this group of older adults with Type 2 diabetes did not have a great deal of weight variability despite participating in a weight loss intervention and exhibited generally good psychological functioning. Thus, exploring weight variability and psychological status in samples with greater variability and poorer psychological status is an important step for future research. The criterion used to assess binge eating (any episodes in past 6 months) did not assess frequency of binge episodes. Finally, though many factors confounding the relationship between weight variability and psychological status were controlled for statistically (e.g. weight loss during intense portion of the intervention), measures of other potential confounds including individual factors such as personality and broader cultural or environmental factors (e.g. accessibility to health-promoting behaviors) were not available.

The findings generated in this paper suggest several potential avenues for further exploration. It is possible that individuals with poorer psychological function are less able to exert consistent levels of behavioral self-control (Hagger, Wood, Stiff, \& D, 2010). These individuals may also be more prone to emotional overeating and may have less stable 
behavioral lifestyle patterns. This lack of stability could result in alternating cycles between strict dieting followed by excessive overeating (i.e. and "all-or-nothing" approach to weight control), and thus greater weight instability. Future studies could explore whether there are novel approaches to weight loss efforts that might be advantageous for these weight unstable individuals. Efforts to address binge eating or depression before starting weight loss have had limited success and possibly have not been studied adequately. However, recent studies suggest that weight loss programs based on Acceptance and Commitment Treatment (ACT) may be particularly well suited to individuals who report emotional overeating and may improve their weight management efforts (Forman et al., 2016). Additionally, future studies could benefit from objectively measuring weight at more frequent intervals and using approaches such as Ecological Momentary Assessment (EMA) to determine the type of psychological factors that immediately precede weight regain and/or weight loss and lead to the increases in weight variability. It would also be useful to compare perceptions of weight cycling with measured weight over time, to see if perceptions of weight control are more psychologically meaningful than actual weight change as one study has suggested (Friedman et al., 1998).

To conclude, the Look AHEAD trial assessed weight variability and psychological status over eight years and found that better psychological status at baseline (i.e. higher mental well-being, lower levels of depressive symptoms, absence of binge eating), was predictive of improved long-term weight management. In contrast, there was limited evidence to suggest that weight cycling was predictive of poorer psychological outcomes (i.e. lower mental wellbeing, more depressive symptoms, and more frequent binge eating). Women were found to be more susceptible to these effects. Research targeting interventions to assist vulnerable populations such as women with risk factors for poor psychological status and weight cycling are indicated.

\section{Supplementary Material}

Refer to Web version on PubMed Central for supplementary material.

\section{Acknowledgments}

Grant funding: (first author was supported by T32 DK 083250 and T32 MH 082761) For complete funding information for the Look AHEAD trial, please refer to Appendix I.

\section{References}

Anderson JW, Konz EC, Frederich RC, Wood CL. Long-term weight-loss maintenance: a metaanalysis of US studies. The American Journal of Clinical Nutrition. 2001; 74(5):579-584. [PubMed: 11684524]

Bartlett SJ, Wadden TA, Vogt RA. Psychosocial consequences of weight cycling. Journal of Consulting and Clinical Psychology. 1996; 64(3):587. [PubMed: 8698953]

Beck AT, Steer RA, Carbin MG. Psychometric properties of the Beck Depression Inventory: Twentyfive years of evaluation. Clinical Psychology Review. 1988; 8(1):77-100. https://doi.org/ 10.1016/0272-7358(88)90050-5.

Brownell KD, Rodin J. Medical, metabolic, and psychological effects of weight cycling. Archives of Internal Medicine. 1994; 154(12):1325. [PubMed: 8002684] 
Casazza K, Fontaine KR, Astrup A, Birch LL, Brown AW, Bohan Brown MM, et al. Myths, presumptions, and facts about obesity. New England Journal of Medicine. 2013; 368(5):446-454. [PubMed: 23363498]

Chen H, Cohen P, Chen S. How Big is a Big Odds Ratio? Interpreting the Magnitudes of Odds Ratios in Epidemiological Studies. Communications in Statistics - Simulation and Computation. 2010; 39(4):860-864. https://doi.org/10.1080/03610911003650383.

Chua JL, Touyz S, Hill AJ. Negative mood-induced overeating in obese binge eaters: an experimental study. International Journal of Obesity. 2004; 28(4):606-610. https://doi.org/10.1038/sj.ijo.0802595. [PubMed: 14968127]

Clark MM, King TK. Eating self-efficacy and weight cycling: a prospective clinical study. Eating Behaviors. 2000; 1(1):47-52. [PubMed: 15001066]

Cutter G, Jeor S, Brunner R, Wolfe P, Foreyt J, Dyer A, Brownell KD. Methodological issues in weight cycling. Annals of Behavioral Medicine. 1996; 18(4):280-289. [PubMed: 18425674]

Dalle Grave R, Todisco P, Oliosi M, Marchi S. Binge eating disorder and weight cycling in obese women. Eating Disorders. 1996; 4(1):67-73.

de Zwaan M, Engeli S, Müller A. Temperamental factors in severe weight cycling. A cross-sectional study. Appetite. 2015; 91:336-342. [PubMed: 25931432]

Diabetes Prevention Program Research Group. Reduction in the incidence of type 2 diabetes with lifestyle intervention or metformin. N Engl J Med. 2002a; (346):393-403. [PubMed: 11832527]

Diabetes Prevention Program Research Group. The Diabetes Prevention Program (DPP) description of lifestyle intervention. Diabetes Care. 2002b; 25(12):2165-2171. [PubMed: 12453955]

Elfhag K, Rössner S. Who succeeds in maintaining weight loss? A conceptual review of factors associated with weight loss maintenance and weight regain. OBR Obesity Reviews. 2005; 6(1):6785.

Fairburn, CG., Beglin, S., Fairburn, CG. Cognitive Behavior Therapy and Eating Disorders. New York: Guilford Press; 2008. Eating Disorder Examination Questionnaire (EDE-Q 60); p. 309-314.

Foreyt JP, Brunner RL, Goodrick GK, Cutter G, Brownell KD, St Jeor ST. Psychological correlates of weight fluctuation. International Journal of Eating Disorders. 1995; 17(3):263-275. [PubMed: 7773263]

Forman EM, Butryn ML, Manasse SM, Crosby RD, Goldstein SP, Wyckoff EP, Thomas JG. Acceptance-based versus standard behavioral treatment for obesity: Results from the mind your health randomized controlled trial. Obesity. 2016; 24(10):2050-2056. [PubMed: 27670400]

Foster GD, Sarwer DB, Wadden TA. Psychological effects of weight cycling in obese persons: a review and research agenda. Obesity Research. 1997; 5(5):474-488. [PubMed: 9385625]

Foster GD, Wadden TA, Kendall PC, Stunkard AJ, Vogt RA. Psychological effects of weight loss and regain: a prospective evaluation. Journal of Consulting and Clinical Psychology. 1996; 64(4):752. [PubMed: 8803365]

French SA, Jeffery RW. Consequences of dieting to lose weight: effects on physical and mental health. Health Psychology. 1994; 13(3):195. [PubMed: 8055855]

Friedman MA, Schwartz MB, Brownell KD. Differential relation of psychological functioning with the history and experience of weight cycling. Journal of Consulting and Clinical Psychology. 1998; 66(4):646. [PubMed: 9735581]

Gallup. Americans' Effort to Lose Weight Still Trails Desire. 2014. Retrieved August 3, 2016, from http://www.gallup.com/poll/179771/americans-effort-lose-weight-trails-desire.aspx

Geliebter A, Aversa A. Emotional eating in overweight, normal weight, and underweight individuals. Eating Behaviors. 2003; 3(4):341-347. https://doi.org/10.1016/S1471-0153(02)00100-9. [PubMed: 15000995]

Gormally J, Black S, Daston S, Rardin D. The assessment of binge eating severity among obese persons. Addictive Behaviors. 1982; 7(1):47-55. https://doi.org/10.1016/0306-4603(82)90024-7. [PubMed: 7080884]

Hagger MS, Wood C, Stiff C, D L. Ego depletion and the strength model of self-control: A metaanalysis. Psychological Bulletin. 2010; 136(4):495-525. https://doi.org/10.1037/a0019486. [PubMed: 20565167] 
Hays RD, Woolley JM. The Concept of Clinically Meaningful Difference in Health-Related Quality of Life Research. PharmacoEconomics PharmacoEconomics. 2006; 18(5):419-423.

Jaeschke R, Singer J, Guyatt GH. Measurement of health status. Controlled Clinical Trials. 1989; 10(4):407-415. https://doi.org/10.1016/0197-2456(89)90005-6. [PubMed: 2691207]

Kensinger GJ, Murtaugh MA, Reichmann SK, Tangney CC. Psychological symptoms are greater among weight cycling women with severe binge eating behavior. Journal of the American Dietetic Association. 1998; 98(8):863-868. [PubMed: 9710655]

Kroenke DK, Spitzer RL, Williams JBW. The PHQ-9. Journal of General Internal Medicine. 2001; 16(9):606-613. https://doi.org/10.1046/j.1525-1497.2001.016009606.x. [PubMed: 11556941]

Kuehnel RH, Wadden TA. Binge eating disorder, weight cycling, and psychopathology. International Journal of Eating Disorders. 1994; 15(4):321-329. [PubMed: 8032347]

Manikandan S. Data transformation. Journal of Pharmacology \& Pharmacotherapeutics. 2010; 1(2): 126-127. https://doi.org/10.4103/0976-500X.72373. [PubMed: 21350629]

Marchesini G, Cuzzolaro M, Mannucci E, Grave RD, Gennaro M, Tomasi F, Melchionda N. Weight cycling in treatment-seeking obese persons: data from the QUOVADIS study. International Journal of Obesity. 2004; 28(11):1456-1462. https://doi.org/10.1038/sj.ijo.0802741. [PubMed: 15314631]

McNair, DM., Lorr, M., Droppleman, LF., et al. Profile of mood states. Educational and Industrial Testing Service; San Diego, CA: 1981.

Messier L, Elisha B, Schmitz N, Gariepy G, Malla A, Lesage A, Strychar I. Weight cycling and depressive symptoms in diabetes: a community-based study of adults with type 2 diabetes mellitus in Quebec. Canadian Journal of Diabetes. 2014; 38(6):456-460. [PubMed: 25034243]

Montani JP, Schutz Y, Dulloo AG. Dieting and weight cycling as risk factors for cardiometabolic diseases: who is really at risk? Obesity Reviews. 2015; 16:7-18. https://doi.org/10.1111/obr.12251. [PubMed: 25614199]

Osborn RL, Forys KL, Psota TL, Sbrocco T. Yo-Yo Dieting in African American Women: Weight Cycling and Health. Ethnicity \& Disease. 2011; 21(3):274-280. [PubMed: 21942158]

Ryan DH, Espeland MA, Foster GD, Haffner SM, Hubbard VS, Johnson KC, Look AHEAD Research Group. Look AHEAD (Action for Health in Diabetes): design and methods for a clinical trial of weight loss for the prevention of cardiovascular disease in type 2 diabetes. Controlled Clinical Trials. 2003; 24(5):610-628. [PubMed: 14500058]

Sherwood NE, Jeffery RW, Wing RR. Binge status as a predictor of weight loss treatment outcome. International Journal of Obesity. 1999; 23(5):485-493. [PubMed: 10375051]

Simkin-Silverman LR, Wing RR, Plantinga P, Matthews KA, Kuller LH. Lifetime weight cycling and psychological health in normal-weight and overweight women. International Journal of Eating Disorders. 1998; 24(2):175-183. [PubMed: 9697016]

Spitzer RL, Devlin M, Walsh BT, Hasin D, Wing R, Marcus M, Agras S. Binge eating disorder: a multisite field trial of the diagnostic criteria. International Journal of Eating Disorders. 1992; 11(3):191-203.

Spitzer RL, Yanovski S, Wadden T, Wing R, Marcus MD, Stunkard A, Horne RL. Binge eating disorder: its further validation in a multisite study. International Journal of Eating Disorders. 1993; 13(2):137-153. [PubMed: 8477283]

Stein RI, Kenardy J, Wiseman CV, Dounchis JZ, Arnow BA, Wilfley DE. What's driving the binge in binge eating disorder?: A prospective examination of precursors and consequences. The International Journal of Eating Disorders. 2007; 40(3):195-203. https://doi.org/10.1002/eat.20352. [PubMed: 17103418]

Stevens J, Truesdale KP, McClain JE, Cai J. The definition of weight maintenance. International Journal of Obesity. 2006; 30(3):391-399. [PubMed: 16302013]

Stojek, MMK., Tanofsky-Kraff, M., Shomaker, LB., Kelly, NR., Thompson, KA., Mehari, RD., Yanovski, JA. Associations of adolescent emotional and loss of control eating with 1-year changes in disordered eating, weight, and adiposity. The International Journal of Eating Disorders. 2016. https://doi.org/10.1002/eat.22636

Strychar I, Lavoie M-È, Messier L, Karelis AD, Doucet É, Prud'Homme D, Rabasa-Lhoret R. Anthropometric, metabolic, psychosocial, and dietary characteristics of overweight/obese postmenopausal women with a history of weight cycling: a MONET (Montreal Ottawa New 
Emerging Team) study. Journal of the American Dietetic Association. 2009; 109(4):718-724. [PubMed: 19328269]

Venditti EM, Wing RR, Jakicic JM, Butler BA, Marcus MD. Weight cycling, psychological health, and binge eating in obese women. Journal of Consulting and Clinical Psychology. 1996; 64(2):400. [PubMed: 8871424]

Vergnaud AC, Bertrais S, Oppert JM, Maillard-Teyssier L, Galan P, Hercberg S, Czernichow S. Weight fluctuations and risk for metabolic syndrome in an adult cohort. International Journal of Obesity. 2007; 32(2):315-321. https://doi.org/10.1038/sj.ijo.0803739. [PubMed: 17968381]

Wadden TA, Foster GD. Weight and Lifestyle Inventory (WALI). Obesity. 2006; 14(S3):99S-118S. https://doi.org/10.1038/oby.2006.289. [PubMed: 16648601]

Wadden TA, Look AHEAD Research. The Look AHEAD study: a description of the lifestyle intervention and the evidence supporting it. Obesity (Silver Spring, Md). 2006; 14(5):737-752.

Wesche-Thobaben JA, The Look AHEAD Research Group. The development and description of the comparison group in the Look AHEAD trial. Clinical Trials (London, England). 2011; 8(3):320329. https://doi.org/10.1177/1740774511405858. 


\section{Table 1}

Baseline Continuous Demographic Characteristics of Analytic Sample $(\mathrm{N}=4,774)$

\begin{tabular}{ll}
\hline Variables & Mean \pm Standard Deviation \\
\hline Age (Years) & $58.7 \pm 6.9$ \\
Body Mass Index $\left(\mathrm{kg} / \mathrm{m}^{2}\right)$ & $35.9 \pm 5.9$ \\
SF-36 Mental Component Summary Score & $54.1 \pm 8.0$ \\
Beck Depression Inventory Score & $5.4 \pm 4.8$ \\
\hline Beck Depression Inventory Score $(\%$ of sample) \\
-0-13: minimal depression 4565 (93.13\%) 4438 (93.3) \\
-14-19: mild depression 260 (5.30\%) 249 (5.2) \\
-20-28: moderate depression $70(1.43 \%) 66(1.4)$ \\
$\cdot 29-63:$ severe depression $7(0.14 \%) 6(0.1)$
\end{tabular}

Health Psychol. Author manuscript; available in PMC 2019 March 01. 


\section{Table 2}

Baseline Categorical Demographic Characteristics and Number of Weight Cycles $(n=4,774)$

\begin{tabular}{|c|c|c|c|c|}
\hline Sex & & & & P-value \\
\hline \multirow[t]{5}{*}{ Female } & $59.8 \%(\mathrm{n}=2,855)$ & Females experiencing... & & $<0.001$ \\
\hline & & No weight cycles & $52.5 \%$ & \\
\hline & & One weight cycle & $30.0 \%$ & \\
\hline & & Two weight cycles & $11.9 \%$ & \\
\hline & & Three or more weight cycles & $5.6 \%$ & \\
\hline \multirow[t]{5}{*}{ Male } & $40.2 \%(\mathrm{n}=1,919)$ & Males experiencing... & & \\
\hline & & No weight cycles & $61.0 \%$ & \\
\hline & & One weight cycle & $26.2 \%$ & \\
\hline & & Two weight cycles & $8.4 \%$ & \\
\hline & & Three or more weight cycles & $4.4 \%$ & \\
\hline \multicolumn{5}{|l|}{ Race/Ethnicity } \\
\hline \multirow[t]{5}{*}{ White } & $63.6 \%(\mathrm{n}=3,037)$ & Whites experiencing... & & 0.43 \\
\hline & & No weight cycles & $55.7 \%$ & \\
\hline & & One weight cycle & $28.7 \%$ & \\
\hline & & Two weight cycles & $9.9 \%$ & \\
\hline & & Three or more weight cycles & $5.5 \%$ & \\
\hline \multirow[t]{5}{*}{ African American } & $15.7 \%(\mathrm{n}=750)$ & African Americans experiencing... & & \\
\hline & & No weight cycles & $55.3 \%$ & \\
\hline & & One weight cycle & $29.6 \%$ & \\
\hline & & Two weight cycles & $10.9 \%$ & \\
\hline & & Three or more weight cycles & $4.1 \%$ & \\
\hline \multirow[t]{5}{*}{ Hispanic } & $12.3 \%(\mathrm{n}=589)$ & & & \\
\hline & & No weight cycles & $55.0 \%$ & \\
\hline & & One weight cycle & $27.7 \%$ & \\
\hline & & Two weight cycles & $11.9 \%$ & \\
\hline & & Three or more weight cycles & $5.4 \%$ & \\
\hline \multirow[t]{5}{*}{ American Indian } & $5.3 \%(\mathrm{n}=254)$ & & & \\
\hline & & No weight cycles & $61.0 \%$ & \\
\hline & & One weight cycle & $24.4 \%$ & \\
\hline & & Two weight cycles & $11.8 \%$ & \\
\hline & & Three or more weight cycles & $2.8 \%$ & \\
\hline \multirow[t]{5}{*}{ Other } & $3.0 \%(n=143)$ & & & \\
\hline & & No weight cycles & $54.5 \%$ & \\
\hline & & One weight cycle & $28.7 \%$ & \\
\hline & & Two weight cycles & $12.6 \%$ & \\
\hline & & Three or more weight cycles & $4.2 \%$ & \\
\hline
\end{tabular}

Health Psychol. Author manuscript; available in PMC 2019 March 01. 


\begin{tabular}{|c|c|c|c|c|}
\hline Sex & & & & P-value \\
\hline \multirow[t]{5}{*}{ Intensive Lifestyle Intervention } & $50.5 \%(\mathrm{n}=2,410)$ & & & 0.056 \\
\hline & & No weight cycles & $57.5 \%$ & \\
\hline & & One weight cycle & $26.8 \%$ & \\
\hline & & Two weight cycles & $10.3 \%$ & \\
\hline & & Three or more weight cycles & $5.4 \%$ & \\
\hline \multirow[t]{5}{*}{ Diabetes Self-Education (DSE) } & $49.5 \%(\mathrm{n}=2,364)$ & & & \\
\hline & & No weight cycles & $54.3 \%$ & \\
\hline & & One weight cycle & $30.3 \%$ & \\
\hline & & Two weight cycles & $10.7 \%$ & \\
\hline & & Three or more weight cycles & $4.9 \%$ & \\
\hline \multicolumn{5}{|l|}{ History of Cardiovascular Disease } \\
\hline \multirow[t]{5}{*}{ Present } & $13.6 \%(\mathrm{n}=360)$ & & & 0.10 \\
\hline & & No weight cycles & $57.7 \%$ & \\
\hline & & One weight cycle & $29.2 \%$ & \\
\hline & & Two weight cycles & $7.7 \%$ & \\
\hline & & Three or more weight cycles & $5.4 \%$ & \\
\hline \multirow[t]{5}{*}{ Absent } & $86.4 \%(\mathrm{n}=4,124)$ & & & \\
\hline & & No weight cycles & $55.6 \%$ & \\
\hline & & One weight cycle & $28.3 \%$ & \\
\hline & & Two weight cycles & $10.9 \%$ & \\
\hline & & Three or more weight cycles & $5.1 \%$ & \\
\hline \multicolumn{5}{|l|}{ Baseline Binge Eating } \\
\hline \multirow[t]{5}{*}{ Present } & $12.7 \%(\mathrm{n}=603)$ & & & 0.035 \\
\hline & & No weight cycles & $50.7 \%$ & \\
\hline & & One weight cycle & $30.5 \%$ & \\
\hline & & Two weight cycles & $12.6 \%$ & \\
\hline & & Three or more weight cycles & $6.1 \%$ & \\
\hline \multirow[t]{5}{*}{ Absent } & $87.3 \%(\mathrm{n}=4144)$ & & & \\
\hline & & No weight cycles & $56.6 \%$ & \\
\hline & & One weight cycle & $28.2 \%$ & \\
\hline & & Two weight cycles & $10.2 \%$ & \\
\hline & & Three or more weight cycles & $5.0 \%$ & \\
\hline
\end{tabular}

Health Psychol. Author manuscript; available in PMC 2019 March 01. 
Table 3

Baseline Psychological Variables Predicting Number of Cycles (none, one, two, three or more) Controlling for Study Arm

\begin{tabular}{|c|c|c|c|c|}
\hline Variable (baseline) & Odds Ratio (OR) & $\begin{array}{c}\text { Lower } 95 \% \text { Confidence interval for } \\
\text { OR }\end{array}$ & $\begin{array}{c}\text { Upper } 95 \% \text { Confidence Interval for } \\
\text { OR }\end{array}$ & P-value \\
\hline Mental Component Score & 0.99 & 0.98 & 1.00 & 0.008 \\
\hline Beck Depression Inventory & 1.02 & 1.01 & 1.03 & 0.001 \\
\hline Binge Eating (yes) & 1.28 & 1.09 & 1.50 & 0.003 \\
\hline
\end{tabular}


Table 4

Baseline Psychological Variables Predicting Weight Coefficient of Variation Controlling for Study Arm

\begin{tabular}{lcccc}
\hline Variable (baseline) & Beta & Lower 95\% Confidence Interval for Beta & Upper 95\% Confidence Interval for Beta & P-Value \\
\hline Mental Component Score & 1.00 & 1.00 & 1.00 & 0.3326 \\
Beck Depression Inventory & 1.01 & 1.00 & 1.01 & 0.0005 \\
Binge Eating (yes) & 4.33 & 4.14 & 4.52 & 3.92 \\
Binge Eating (no) & 3.85 & 3.79 & $<0.0001$ \\
\hline
\end{tabular}




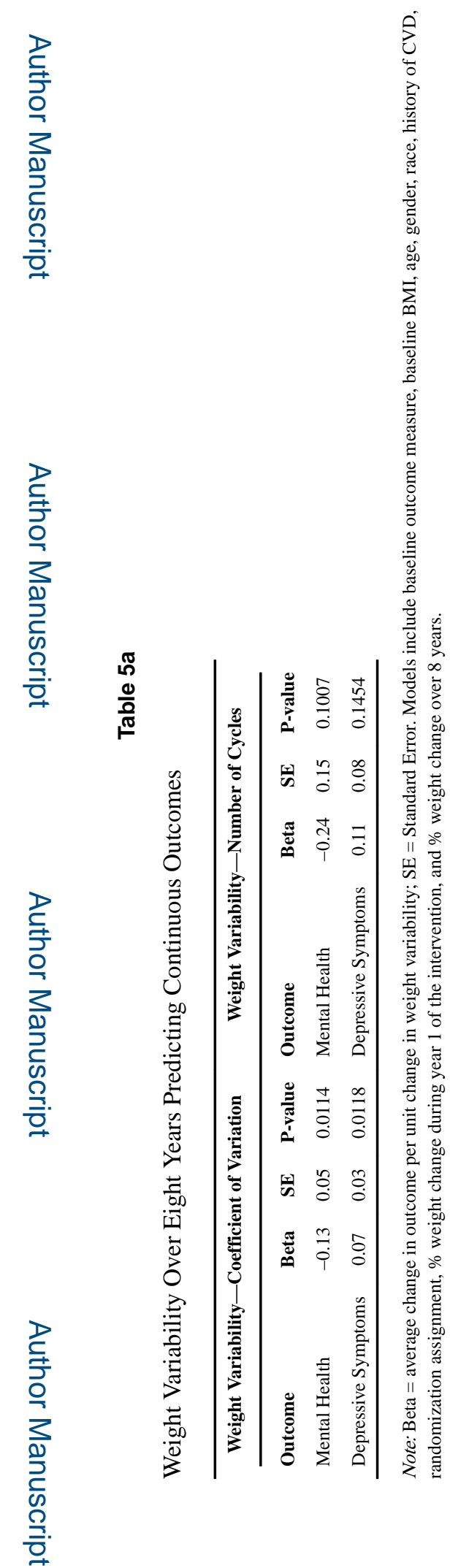

Health Psychol. Author manuscript; available in PMC 2019 March 01. 


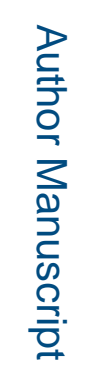

로을

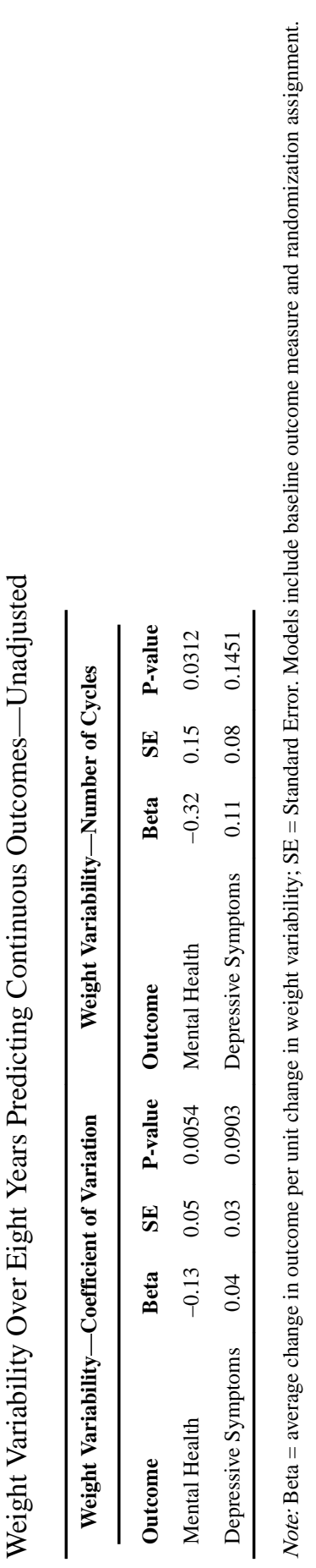

Health Psychol. Author manuscript; available in PMC 2019 March 01. 


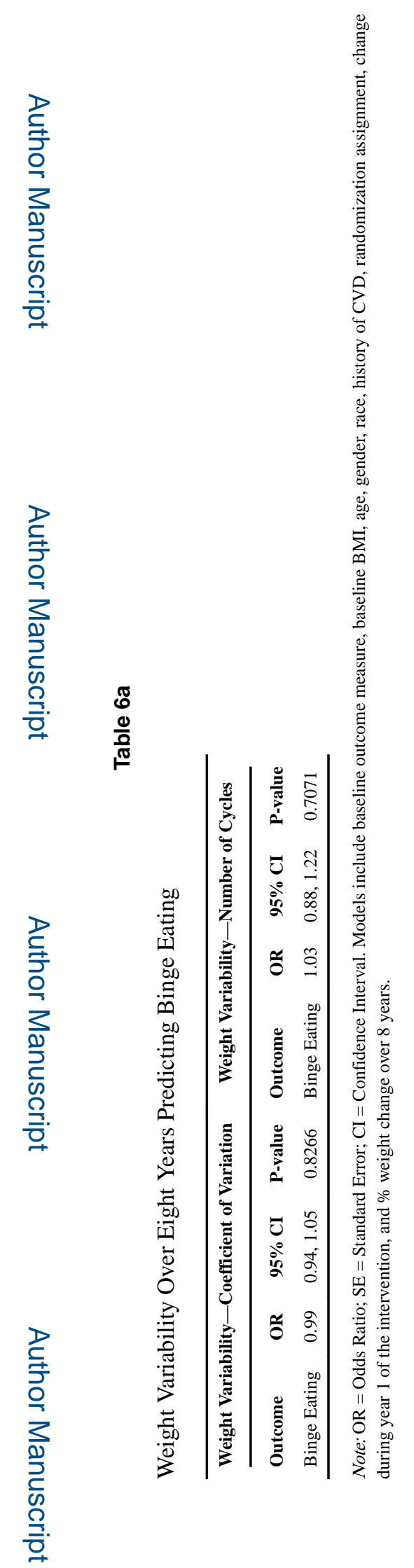

Health Psychol. Author manuscript; available in PMC 2019 March 01. 

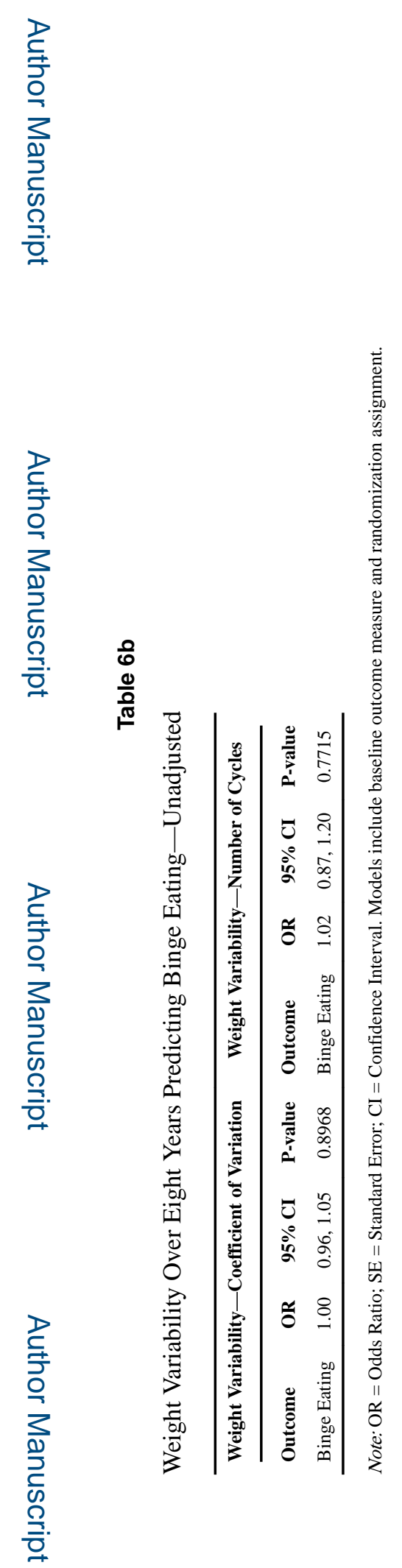

Health Psychol. Author manuscript; available in PMC 2019 March 01. 